\title{
Time Constant of Innovation Effects Doubling
}

\author{
Vladimir Fedorovich Minakov \\ Tatyana Evgenyevna Minakova ${ }^{2}$ \\ Armen Shagenovich Galstyan ${ }^{3}$ \\ Anastasia Alexandrovna Shiyanova ${ }^{3}$ \\ ${ }^{1}$ Saint Petersburg State University of Economics \\ ${ }_{2}^{2}$ National Mineral Resources University (Mining University) \\ ${ }^{3}$ North Caucasian Federal University \\ Email: mamychev@yandex.ru
}

Doi:10.5901/mjss.2015.v6n3s6p307

\section{Abstract}

The article suggests reflecting the dynamics of evolutionary innovations through time constant of the change in the innovative effect. Such metric numerically equals the period at which the effect of evolutionary innovations changes a fixed number of times. The effect change factor can possess any value suitable for each specific type of the innovative product. The index characterizing the dynamics of the evolutionary innovations - the time constant of the innovative processes effect has been introduced. The effects can be characterized by the improvement in the innovative products properties, the increase in the effectiveness, etc. This index can be applied both to the particular types of the innovative products and to their range, to the innovative development of national and world economies. It allows making compatible innovative processes of different scale. In addition, the time constant of the innovative processes provides the possibility to evaluate and choose the innovations existing in the market according to their compliance with the current dynamics of the innovative development.. The suggested index characterizes both particular innovative products and their range.

Keywords: Innovation, model, innovation, logistic function, exponential function.

\section{Introduction}

The classification of innovations according to the degree of their influence on the economy and mass production suggests that there are (Kondratyev, N.D, 2002) radical (providing revolutionary effect change comparing with the analogues, or having no analogues) and evolutionary (modernizing and gradually increasing the effect comparing with analogues) innovations.

Nuclear power plants can provide the examples of revolutionary innovations. Beginning with Obninskaya nuclear power plant which was set in operation in 1954 (with the power of 5 megawatt) they became widespread. By now in Russia alone their installed capacity has achieved 25266 megawatt, and their proportion in the country's electricity production is about $11,2 \%$. It should be mentioned that in European countries importing carbon fuels the share of nuclear power plants in electricity production reaches $74 \%$ (France).

The revolutionary innovation was the first artificial satellite (1957) which transmitted bits of signal straight to the Earth's population. Nowadays, satellite communication captured a huge niche in television, radio broadcasting, telephone industries, transmission of Internet and other computer networks data, GPS and GLONASS navigation and in a variety of other telecommunication systems and service technologies. Other examples of revolutionary innovations are the ones of Apple Company and Steve Jobs: a PC, i-Pad and i-Phone.

\section{Dynamics for Penetration of Innovations}

The dynamics for diffusion of these innovations can be easily modeled through the mathematical description of the diffusion process (Minakov, V.F. Minakova T.E. \& Barabanov M., 2012):

$$
d V=r \cdot V\left(1-V / V_{m}\right) \cdot d t .
$$


where $V$ is the current amount of innovations used in the environment; $V_{m}$ is the level of the greatest innovation diffusion (for example, sales) in the environment after it has been saturated with the innovative product; $r$ is the index of innovation diffusion (coefficient of innovation diffusion).

Its solution is the following logistic function:

$V=\frac{V_{m}}{1+e^{p-r \cdot t}}$.

where $p$ is the index of time delay in the beginning of the innovation diffusion relating to the beginning of the coordinate system (lag of the innovation launch within the coordinate system); $e$ is the base of the natural logarithm.

Fugure 1 shows Google company's information on the expansion of the innovative form of marketing - mobile, i.e. revenue effect of providing this service (curve 1) (Marin Software, 2012), as well as the results of function modeling of the same index (curve 2). These data provide a good illustration for the adequacy of this model.

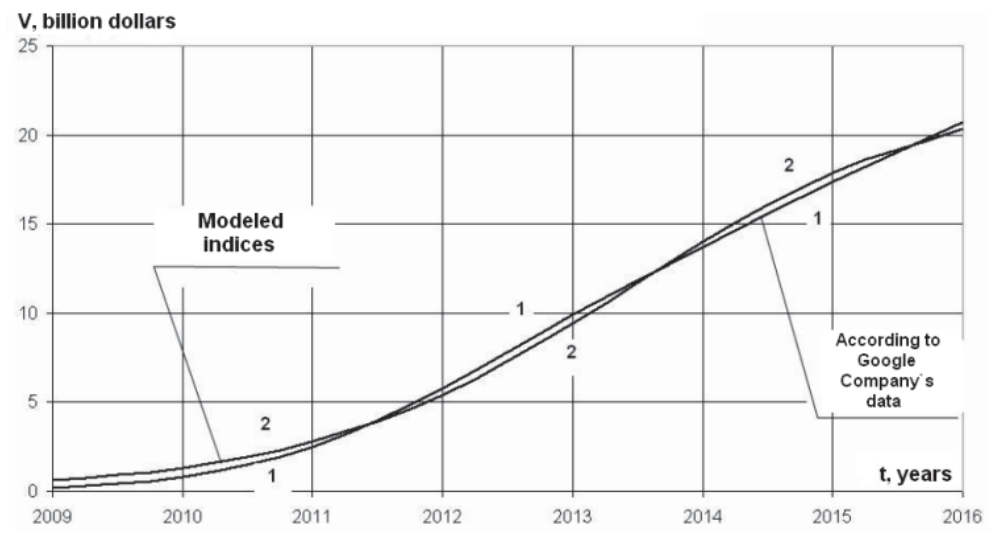

Figure 1. Google's revenue from mobile marketing

However, these models are not suitable for the evolutionary innovations for a number of reasons:

1) evolution and modernization are based on the results (effects) of the previous innovation which is not taken into consideration by the logistic function;

2) every modernization characterizes a very limited range of the changes in the characteristics in the big flow of innovative products.

\section{The Aim of Research Work and Mathematical Model}

For the aforesaid reasons the models of evolutionary innovations need to be developed in regard to the sequence of such innovations within the great number of modernizations. The aim of this article is to prove the need for presenting modern innovative processes of evolutionary type in the form of adequate economic and mathematical model.

To characterize the qualities of time series expressing quantitative results of the innovative processes (characteristics of innovative products properties, their quality, the amount of consumption, etc.) we suggest applying the time constant of innovative processes which equals the time of a fixed number of the changes in innovative products characteristics, for instance, in "e" times (where $\boldsymbol{e}$ is the base of the natural logarithm). The alternatives to $\mathbf{e}$ multiplicity of the changes in the results of the evolutionary innovative processes are 2 multiplicity, 10 multiplicity (one order), other real multiplicity which can be suitable for the representation of innovation efficiency.

A mathematical interpretation for this representation of the improving innovation efficiency is the exponential function:

$V_{t}=V_{t_{0}} \cdot e^{\left(t-t_{0}\right) / T}$,

where $T$ is the time constant of the innovative process;

$V_{t_{0}}$ is the initial value of the product characteristics prior to its modernization (prior to evolutionary innovation); ${ }_{0}$ is the time point of the beginning of the evolutionary innovative process.

The time constant can be calculated from any two values of the innovative process effect characteristics $V_{t_{i}}, V_{t_{j}}$. 
Indeed,

$$
\begin{aligned}
& V_{t_{i}}=V_{t_{0}} \cdot e^{\left(t_{i}-t_{0}\right) / T}, \\
& V_{t_{j}}=V_{t_{0}} \cdot e^{\left(t_{j}-t_{0}\right) / T},
\end{aligned}
$$

Let us transform (4) and (5):

$$
\begin{aligned}
& V_{t_{0}}=V_{t_{i}} / e^{\left(t_{i}-t_{0}\right) / T}, \\
& V_{t_{0}}=V_{t_{j}} / e^{\left(t_{j}-t_{0}\right) / T},
\end{aligned}
$$

Due to the equality of the left sides (6) and (7) their right sides can be also equaled:

$$
V_{t_{i}} / e^{\left(t_{i}-t_{0}\right) / T}=V_{t_{j}} / e^{\left(t_{j}-t_{0}\right) / T},
$$

Otherwise:

$$
V_{t_{j}} / V_{t_{i}}=e^{\left(t_{j}-t_{0}\right) / T} / e^{\left(t_{i}-t_{0}\right) / T},
$$

Taking the logarithm (9), we obtain:

$$
\ln \left[e^{\left(t_{j}-t_{0}\right) / T}\right]-\ln \left[e^{\left(t_{i}-t_{0}\right) / T}\right]=\ln V_{t_{j}}-\ln V_{t_{i}},
$$

whence:

$$
\begin{aligned}
& \left(t_{j}-t_{0}\right) / T-\left(t_{i}-t_{0}\right) / T=\ln V_{t_{j}}-\ln V_{t_{i}}, \\
& {\left[\left(t_{j}-t_{0}\right)-\left(t_{i}-t_{0}\right)\right] / T=\ln V_{t_{j}}-\ln V_{t_{i}},} \\
& \left(t_{j}-t_{i}\right) / T=\ln V_{t_{j}}-\ln V_{t_{i}}, \\
& T=\left(t_{j}-t_{i}\right) /\left(\ln V_{t_{j}}-\ln V_{t_{i}}\right) .
\end{aligned}
$$

It is important to mention that the most widespread notation form of the exponential function with «e» base characterizes 2.72 multiplicity of the change per time constant T which is less convenient than, for instance, 2 multiplicity. Consequently, notation form of the exponential function with 2 base is more suitable. To pass to such exponential function we have to take into account that

$$
e=2^{\log _{2} e} \text {, }
$$

and

$$
\log _{2} e \approx 1,44 \text {. }
$$

Now the exponential function (3) takes the form

$$
V_{t}=V_{t_{0}} \cdot 2^{1,44 \cdot\left(t-t_{0}\right) / T} \text {. }
$$

With 2 base of the exponential function a proper doubling time constant of innovations effect should be introduced

$$
T_{2}=T / 1,44 \text {. }
$$

In this case (17) acquires a traditional form:

$$
V_{t}=V_{t_{0}} \cdot 2^{\left(t-t_{0}\right) / T_{2}} \text {. }
$$

It is important that $T_{2}$ has the same meaning as the time constant of the exponential function, but the characteristics of the innovation efficiency change 2 times

\section{Verification of the Model with Observation Results}

During the period of observations which lasted 120 years it was defined that the effect of innovations in equipment leads to the double improvement of its characteristics every 10 years (doubling time constant equals 10 years) (Klimenko, S.V., Bono P. \& Jorge J., http://www.tup.km.ua/citforum/Aud/ofis96/107.htm, 2015). For a number of equipment types the exponential rule of their improvement is described as demonstrating higher rates. Thus, the power of turbine generators doubles with the time constant of 7-10 years (Magnet for three millennia, http://www.valtar.ru/Magnets2/mag_2_16.htm). The doubling time constant for the power of computer systems is 1.5 years (Smart 'world, http://club.cnews.ru/BZZN.ru), for the semiconductor switch density per unit area (Moore's law // wikipedia. URL: http://en.wikipedia.org/wiki/ Moore's_law) is 24 months (this pattern being a particular case is well-known as Moore's law). 
It is also pertinent to note that the growth rate of the information volume during long time periods (comparing with the time required to analyze current processes) is characterized by the same law: the volume of information produced by humanity doubles within the technological mode in a fixed period of time. So, the current rates of its growth are characterized by the doubling time which equals 18 months Petersburg International Economic Forum (2012). This index coincides with the time constant of the current growth of digital data which allows determining that it is the latter that is dominant in volume.

The suggested index - time constant of innovations evolution characterizes both every innovative product and the process of the innovative development of national and world economies Rogers, E.M. (1992); Rogers, E.M. (2003) \& Bass, Frank M. (2004) . Indeed, the sum of innovative effects different in innovation diffusion rates (figure 2) (with $k_{i T}=T_{i} / T$ coefficients) and degrees (with $k_{i m}=V_{m i} V_{m}$ coefficients) comparing with one (with $V_{m}, T$ coefficients):

$$
V_{\Sigma}=\sum_{i=1}^{N} k_{i m} \cdot V_{0 i} \cdot e^{t /\left(k_{i T} \cdot T\right)}
$$

is close to the exponential law, as it can be seen on figure 3 .

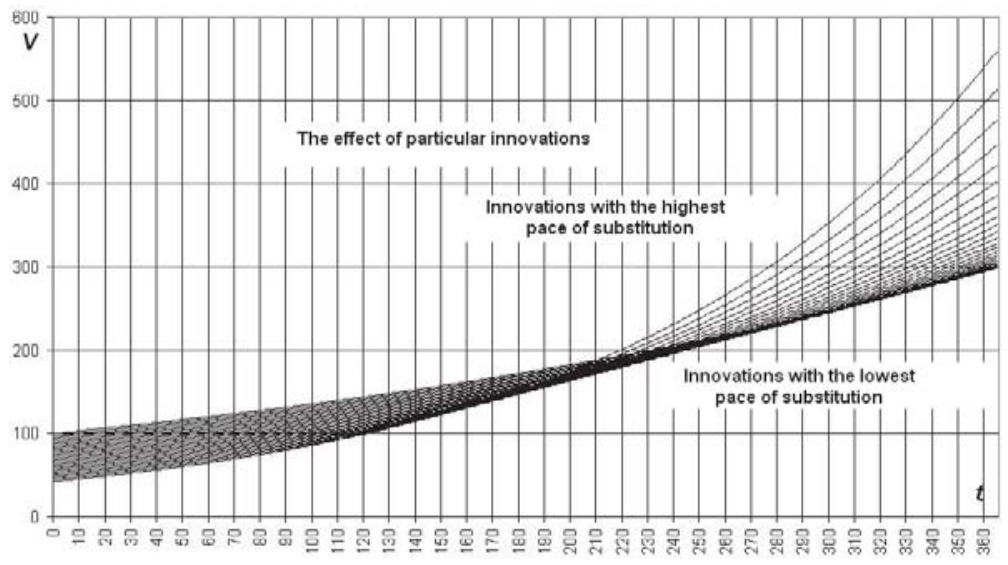

Figure 2. The efficiency (for example, financial) of particular innovations

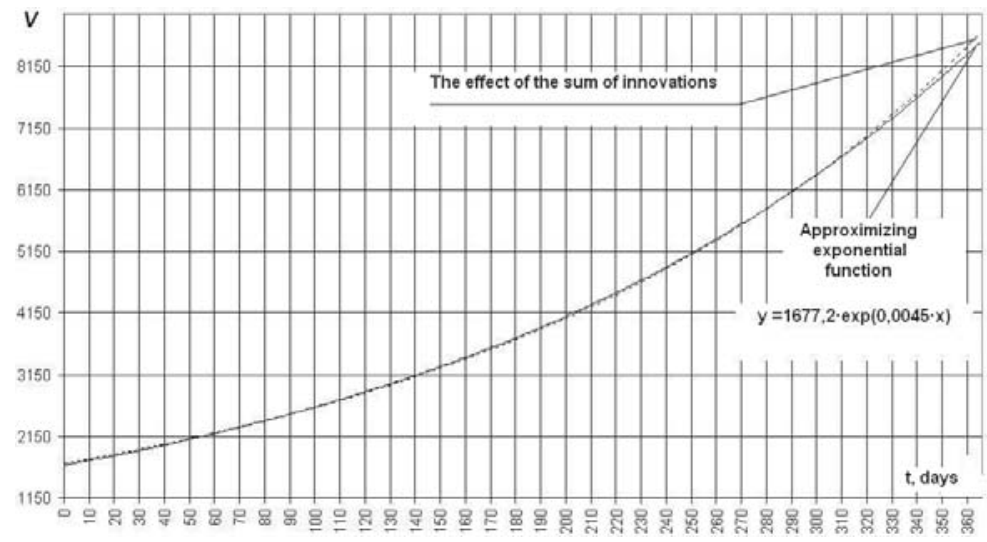

Figure 3. The efficiency (for example, financial) of the sum of innovations

The resulting exponential function of the innovation effects sum is:

$$
V_{\Sigma}=1677 \cdot e^{0,0045 \cdot t}
$$

or

$$
V_{\Sigma}=1677 \cdot e^{t / T}=1677 \cdot e^{t / 222} \text {. }
$$

Thus, the time constant of the resulting innovations effect is 222 days, and the effect grows according to the exponential law - function (22). 
In addition, figures 2 and 3 show that the exponential growth of the innovative products characteristics leads to their little (almost fading) growth at the starting point of the time series (it is particularly typical of mapping the time periods much longer than the time constant of the innovation efficiency). In this respect it is better to illustrate the changes in the innovations characteristics within semilogarithmical coordinate system, where the time axis remains linear and the vertical axis (innovation characteristics changing according to the exponential function) is logarithmic. To illustrate the use of these coordinates figures 4 shows the dynamics of the innovative processes having substantially different time constants.

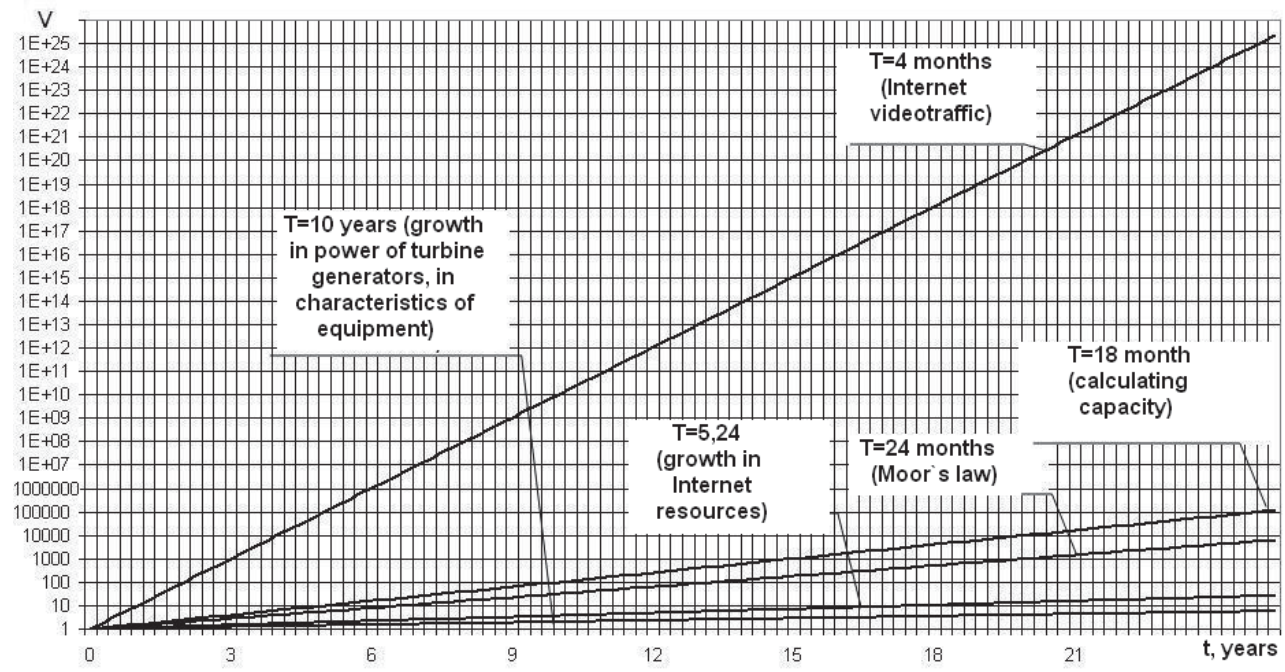

Figure 4. The dynamics of the evolutionary innovation efficiency

Thus, the time constant of the innovation efficiency quantitatively characterizes the dynamics of the evolution in the innovative products properties. Due to it consumers can make reasonable decisions on the choice of goods taking into consideration the prospect required in each particular case. Investors can use this metric to make a choice of those innovative projects that will be competitive in the market if their indices are higher than those of the figure 4 trend and to reject the unpromising ones in the opposite case.

Nowadays, such choice of the strategy is particularly relevant when the crisis raises the demand for the efficient investment in innovations Schweitzer, F. (2008) \& Chiang, S.-Y. (2012).

\section{Conclusion}

The index characterizing the dynamics of the evolutionary innovations - the time constant of the innovative processes effect has been introduced. The effects can be characterized by the improvement in the innovative products properties, the increase in the effectiveness, etc. This index can be applied both to the particular types of the innovative products and to their range, to the innovative development of national and world economies. It allows making compatible innovative processes of different scale. In addition, the time constant of the innovative processes provides the possibility to evaluate and choose the innovations existing in the market according to their compliance with the current dynamics of the innovative development.

\section{References}

Kondratyev, N.D (2002). Big cycles of an environment and anticipation theory. M.: Economyka. pp. 768.

Minakov, V.F. Minakova T.E., Barabanov M. (2012) Экономико-математическая модель этапа коммерциализации жизненного цикла инноваций // Научно-технические ведомости Санкт-Петербургского государственного политехнического университета. Экономические науки. St. Petersburg State Polytechnical University Journal. Economics. Т. 2-2. № 144. pp. 180-184.

Marin Software. Report: 25 Percent Of Paid-Search Clicks Will Come From Mobile By December. URL: http://katemossguru.com/blog (дата обращения: 22.07.2012). 
Klimenko, S.V., Bono P. \& Jorge J. revolution or a fad? // Server Information Technologies. URL: http://www.tup.km.ua/citforum/Aud/ ofis96/107.htm (дата обращения: 17.02.2015).

Magnet for three millennia. URL: http://www.valtar.ru/Magnets2/mag_2_16.htm (дата обращения: 17.02.2015).

Smart 'world. URL: http://club.cnews.ru/BZZN.ru.

Moore's law // wikipedia. URL: http://en.wikipedia.org/wiki/Moore's_law.

Petersburg International Economic Forum (2012). Сессия: цифровая обработка и сбор данных как важный инструмент принятия решений. Роль «цифрового капитала» в выработке корпоративной стратегии. URL: http://www.forumspb.com/ru/2012/.

Rogers, E.M. (1992) A History of Communication Theory. An Introduction to Planned Communication. - London etc. pp. 62.

Rogers, E.M. (2003) Diffusion of Innovations, Fifth Edition. Free Press, New York.

Bass, Frank M. (2004) New Product Growth Model for Consumer Durables // Management science. № 15. pp. 215-227.

Schweitzer, F. (2008) The Epidemics of Donations: Logistic Growth and Power-Laws/F. Schweitzer, R. Mach // PLoS ONE. № 3 (1). http://www.plosone.org/l

Chiang, S.-Y. (2012) An application of Lotka-Volterra model to Taiwan's transition from $200 \mathrm{~mm}$ to $300 \mathrm{~mm}$ silicon wafers // Technological Forecasting and Social Change. V. 79. № 2. pp. 383-392. 